\title{
Stigmasterol-3-O-glucoside, an allelopathic molecule responsible for pest resistance of Thenkaali (AAB), a Musa cultivar against Odoiporus longicollis [Olivier]
}

\author{
K. J. Kavitha ${ }^{1}$, J. Anil John ${ }^{2}$ and D. A. Evans ${ }^{1, *}$ \\ ${ }^{1}$ Department of Zoology, University College, Thiruvananthapuram 695 034, India \\ ${ }^{2}$ Phytochemistry and Phytopharmacology Division, JNTBGRI, Palode, Thiruvananthapuram 695 562, India
}

\begin{abstract}
Thenkaali, a Musa cultivar with genetic constitution AAB shows no infestation by Odoiporus longicollis Olivier, the pseudostem borer (PSB) under field conditions. The whole life cycle of this highly destructive pest is completed within the host plants. Thenkaali possesses high content of secondary metabolites such as total phenols, total flavonoids and elevated activity of related enzymes such as phenylalanine ammonia lyase, polyphenol oxidase and peroxidase. Rearing of larvae of PSB in the live pseudostem of Thenkaali has resulted in $100 \%$ mortality within one week. The pseudostem possesses a larvicidal compound stigmasterol-3-O-glucoside, a steroid present at very low concentration (less than $0.0001 \%$ ). The compound induces strong allelopathy on PSB, resulting in haemocytopenia and numerical changes in haemocytes. Other allelopathic changes are hyperprotenemia of haemolymph with changes in protein profile and sharp decrease in total free amino acids. The allelopathic compound induces antagonistic response on two proteolytic enzymes, evidenced by elevation of cathepsin $D$ and inhibition of leucine amino peptidase activity. Imbalance in the activity of aspartate amino transferase and alanine amino transferase results in increased catabolism of amino acids, which leads to sharp increase in the haemolymph uric acid. Toxicity by stigmasterol-3-O-glucoside results in sharp elevation of 20 hydroxy ecdysone in the haemolymph and subsequent disruption of the endocrine system of the larvae might have contributed to cessation of feeding activity and its death.
\end{abstract}

Keywords: Allelopathy, Musa cultivars, Odoiporus longicollis, pest resistance, secondary metabolites.

INDIA is one of the major biodiversity centres of Musa cultivars and stands first in the world in the production of bananas and plantains ${ }^{1}$. Musa cultivars are sterile plants which are unable to set viable seeds and are propagated vegetatively by suckering. These plants are originated through natural hybridization of two plants under a single

\footnotetext{
*For correspondence. (e-mail: drevansda@gmail.com)
}

genus, Musa acuminata (A genome) and M. balbisiana (B genome $)^{2}$. The cultivars are mostly triploid $2 n=$ $3 x=33$ ) and those with short, robust pseudostem and broad leaves come under the genome constitution of $\mathrm{AAA}$, while plantains $\mathrm{AAB}$ or $\mathrm{AB}$ and starchy cooking banana $\mathrm{ABB}$, all are equally diverse with major influence of ecological factors on their distribution and survival ${ }^{3}$. A few diploid cultivars with genome constitution AA are also cultivated, but yield comparatively small fruit bunches and have chromosome number $2 n=2 x=22$, which is also common in the agro-ecosystem ${ }^{4}$. The cultivars of Musa have diversified into complex germplasm pool, mostly through somatic mutation ${ }^{5}$ and somaclonal variation $^{6}$. The Cavendish AAA group of Musa cultivars is increasingly susceptible to a range of fungal and viral diseases and also to insect pests, which necessitate chemical control measures.

The diversity of Musa cultivars in India is high and the commercially viable cultivars (CVCs) usually have desirable characters such as large fruit bunch, palatable ripe fruits, short duration to set flowers, etc. However, these CVCs are highly susceptible to pseudostem borer, Odoiporus longicollis [Olivier] $]^{7,8}$. They possess very low quantities of total phenols (TP), total flavonoids (TF) and very low activities of phenylalanine ammonia lyase (PAL), polyphenol oxidase (PPO) and peroxidase (PO) ${ }^{9,10}$.

O. longicollis is the most destructive pest in the commercial cultivation of Musa ${ }^{11}$. The Musa cultivars have been categorized into highly susceptible (HS), susceptible (S), nonpreferred (NP) and resistant (R) based on the preference of $O$. longicollis ${ }^{7,8}$. Rearing of larvae in live pseudostem of HS, S and NP cultivars has resulted in completion of life cycle, but in R cultivars has resulted in mortality of larvae in one week ${ }^{7,8}$. If $\mathrm{HS}$ or $\mathrm{S}$ cultivars were available in the agro-ecosystem, mother weevil never visited NP cultivars. They showed sporadic attack by the pest when away from the vicinity of HS or S culti$\operatorname{vars}^{7,8}$. Rearing of $O$. longicollis in live $\mathrm{R}$ cultivars has resulted in mortality of larvae in seven days. Analysis of 85 cultivars of Musa in Kerala, India showed that 28 of them are under $\mathrm{R}$ category and all cultivars possessed 
very high content of TP, TF and elevated activity of PAL, $\mathrm{PPO}$ and $\mathrm{PO}^{9,10}$.

Thenkaali (Figure 1a), a Musa cultivar of genome constitution AAB is among the $\mathrm{R}$ category cultivars, identified in Pathanamthitta district of Kerala. It is a commercially non-viable cultivar identified through detailed field study supplemented with GIS Arc software ${ }^{7}$. Thenkaali showed strong allelopathic interactions against $O$. longicollis, when reared in the live pseudostem. Bioassay-guided extraction of dry pseudostem powder of Thenkaali using organic solvents and subsequent fractionation of the active larvicidal extract resulted in the isolation and characterization of the allelopathic molecule, which forms the subject matter of this study.

\section{Materials and methods}

\section{Experimental organism}

Larvae of $O$. longicollis dissected out from the infested pseudostem of susceptible cultivars were used. Larvae up to second instar are small and highly sensitive to handle. Fourth-instar larvae are preferably large and voracious feeders, and hence these were used for the study.

\section{Rearing of larvae in the live pseudostem}

Four-month-old Musa cultivars with trunk circumference of $25-30 \mathrm{~cm}$ were used for the study. The crown of the plant was cut in such a way that the live stump of $1 \mathrm{~m}$ height remained in viable state. Larvae of $O$. longicollis (six numbers) were carefully placed at the free end so that they could bore into the pseudostem. The free end was covered with a piece of mosquito net and kept undisturbed for eight days. On the eighth day, the pseudostem was cut $15 \mathrm{~cm}$ below the first cut, and the larvae were carefully taken out and compared with those in susceptible cultivars. If all the larvae were dead on the eighth day

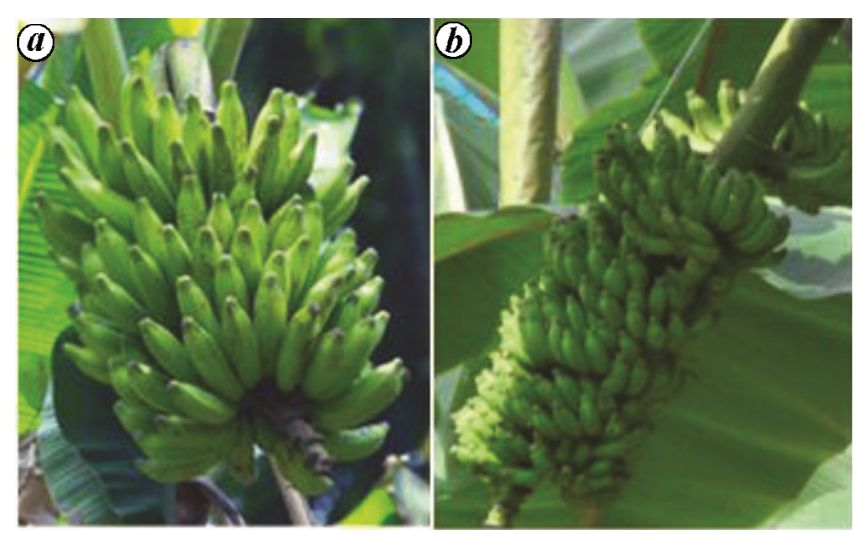

Figure 1. a, Musa cultivar Thenkaali (AAB). b, Palayankodan (AAB). the cultivar was considered as resistant to $O$. longicollis infestation $^{7,8}$. Palayankodan (Figure $1 b$ ), a CVC and HS cultivar with genome constitution $\mathrm{AAB}$ was used as control $^{8}$.

\section{Host plant enzymes}

Tender leaf at unfurled cigar state of $20-30 \mathrm{~cm}$ length was cut from the free terminal $(5 \mathrm{~cm})$ and kept in ice-cold conditions till further processing. The content of $\mathrm{TP}^{12}$, $\mathrm{TF}^{13}$, and activities of enzymes such as $\mathrm{PAL}^{14}, \mathrm{PO}^{15}$ and $\mathrm{PPO}^{16}$ were assayed according to standard protocols.

\section{Phytochemical isolation of compounds}

Pseudostem of Musa cultivars which are highly susceptible or resistant to infestation were cut vertically into small chips and dried under shade (at ambient temperature $28^{\circ}-33^{\circ} \mathrm{C}$ ) for three weeks, after which they were ground to a fine powder. Thereafter, $400 \mathrm{~g}$ sample was kept overnight in organic solvents and first extracted by petroleum ether, followed by acetone and finally with methanol. The extracts were filtered and concentrated in rotary vacuum evaporator and larvicidal activity was observed as described in the following section. As the larvicidal activity was found only in the acetone extract, it was subjected to column chromatography using a suitable solvent system. Elution was carried out by gradient polarity system starting from $100 \%$ petroleum ether to $100 \%$ methanol. Each fraction was monitored by TLC and they were combined, based on their TLC profiles, which resulted in nine fractions. Larvicidal activity of each fraction was noted. As the eighth fraction showed larvicidal activity, it was again subjected to column chromatography to isolate the specific compound in pure form.

\section{Spectral analysis of active molecule}

NMR $\left({ }^{1} \mathrm{H},{ }^{13} \mathrm{C}, \mathrm{HMBC}\right.$ and HSQC) and LC-Q-T-MS analysis of the active compound were done at IIRBS and School of Environmental Science, Mahatma Gandhi University, Kottayam, Kerala.

\section{Testing of larvicidal activity}

Freshly cut pseudostem of $100 \mathrm{~g}$ pieces of circular rods from Palayankodan cultivar was used for the study. Active compound or extract was dissolved in water containing $0.5 \%$ Tween. The dissolved extract $(2 \mathrm{ml})$ from susceptible or resistant pseudostem or active molecule in known concentration was injected into the $100 \mathrm{~g}$ piece of pseudostem evenly at ten sites using insulin syringe. Each larva was allowed to bore into the pseudostem. Healthy 


\section{RESEARCH ARTICLES}

fourth-instar larvae were used for the study. Percentage mortality was calculated as follows ${ }^{17,18}$

$$
\frac{\left(\begin{array}{c}
\text { Percentage of test mortality }- \\
\text { percentage of control mortality }
\end{array}\right)}{100-\text { percentage of control mortality }} \times 100 \text {. }
$$

Every day each piece containing a single larva inside was kept close to the ear of the observer six times (every $30 \mathrm{~min}$ continuously for $3 \mathrm{~h}$ ) to hear the feeding sound, which is an indication of the health of the larva inside. Wriggling movements of the apodous larvae and creamywhite colour of the body are other conspicuous characters which indicate health of the larvae. They became flaccid and gradually acquire a bluish colouration at death. Each piece with a larva was placed in a plastic container covered with a cheese cloth and kept in a dark, cool place. Fresh piece of pseudostem, administered with the test sample was provided once in two days. On the eighth day, the pseudostem pieces were carefully dissected to observe the larvae. Minimum quantity of active compound required for mortality within seven days was studied. As $100 \%$ mortality of the larvae in live pseudostem of Thenkaali cultivar occurred between the seventh and eighth day, seven days was taken as the observation limit to assess toxicity ${ }^{9}$.

\section{Haematological studies}

The larvae on the fourth day of observation (before death) were used for study. They were kept on a glass plate with ice cubes placed above and a small cut was given on the ventral side with great care, not to puncture the gut, to collect haemolymph. Total haemocyte count was measured using by haemocytometer. The number of haemocytes per cubic millimetre was calculated using the formula suggested by Jones ${ }^{19}$. A thin film of smear was prepared using haemolymph to study the differential hemocyte count. The smear was air-dried and stained using Giemsa stain for $20 \mathrm{~min}$. The slide was then washed in running water to remove excess stain. The slides were then air-dried and the number of different types of haemocytes of treated and control samples was counted. The percentage of different types of haemocytes in each of the samples was also calculated.

\section{Assay of larval enzymes}

Cell-free haemolymph of fourth-instar larvae was used for the study. Quantitative estimation of protein ${ }^{20}$, total free amino acids ${ }^{21}$, transaminases (aspartate amino transferase [E.C. 2.6.1.1] and alanine amino transferase [E.C. 2.6.1.2] $)^{22}$, leucine amino peptidase [E.C. 3.4.11.1] ${ }^{23}$ and cathepsin D [E.C. 3.4.23.5] ] $^{24}$ was done according to standard protocols. Enzyme immunoassay of 20-hydroxy ecdysone was done using an enzyme kit (Bertin Pharma, France $)^{25}$. Uric acid content was estimated by uricaseperoxidase end-product assay kit (Span Diagnostics) ${ }^{26}$.

Electrophoresis of cell-free haemolymph of larvae was carried out using the method devised by Laemmeli ${ }^{27}$; $12 \%$ resolving gel and $4 \%$ stacking gel were used for SDS-PAGE. The electropherogram was subjected to GelDoc analysis.

\section{Statistical analysis}

The results obtained are represented as mean \pm standard deviation. Statistical comparison of results was performed by one-way analysis of variance [ANOVA] using SPSS 21 software. The results are considered statistically significant if $P \leq 0.05$ (ref. 28).

\section{Results}

An indigenous Musa cultivar of Kerala, locally called as Thenkaali (AAB), did not get infested by O. longicollis under field conditions. Rearing of $O$. longicollis larvae in the live pseudostem of this cultivar resulted in mortality within a week. The cultivar possessed very high contents of TP and TF compared to pest-susceptible and commercially viable cultivar, Palayankodan (AAB) (Figure 2). Activities of host plant enzymes such as PAL, PO and PPO were also very high in pest-resistant cultivar (Figure 3).

Systematic extraction of dry powder of pest-resistant pseudostem resulted in larvicidal activity in the acetone extract, which was fractionated into nine fractions by column chromatography. The eighth fraction $(8: 92 \%$ methanol: chloroform mixture) showed larvicidal activity, which on sub-fractionation under column chromatography (92:8, chlorofom: methanol) resulted in the isolation of two compounds in pure form. One of the compounds showed larvicidal activity at an extremely low dose of $1 \mathrm{mg}$ in $100 \mathrm{~g}$ fresh pseudostem (Table 1).

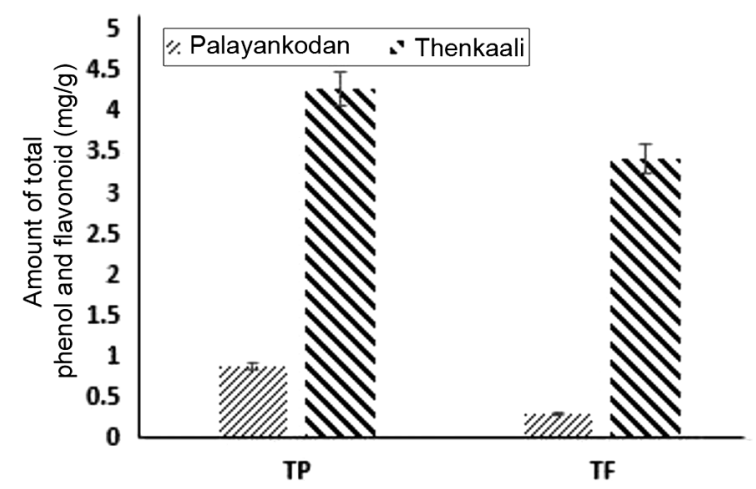

Figure 2. Total phenols and total flavonoids content of resistant and susceptible Musa cultivars. All values are mean $\pm \mathrm{SD}, n=6$. Value of each parameter is significantly different in Duncan's multiple range test at 0.05 level. 
NMR $\left(\mathrm{H}^{1}\right.$ and $\left.\mathrm{C}^{13}\right)$ and LC-Q-T-MS revealed that the compound was a glycoside and was named stigmasterol3-O-glucoside (Figure 4). ESI-MS: $m / z \quad 575.2375$ $[\mathrm{M}+\mathrm{H}]+{ }^{1} \mathrm{H} \mathrm{NMR} \quad\left(\mathrm{CDCl}_{3}-\mathrm{CD}_{3} \mathrm{OD}, \quad 400 \mathrm{MHz}\right): \quad \delta$ (ppm): 5.42 (1H, br.s, H-6), 5.09-5.21 (2H, m, H-22 and H-23), 4.47 (1H, br.s, H-1'), 3.28-3.93 (6H, m, H-2'-H$\left.6^{\prime}\right) .{ }^{13} \mathrm{C}-\mathrm{NMR} \quad\left(\mathrm{CDCl}_{3}-\mathrm{CD}_{3} \mathrm{OD}, 100 \mathrm{MHz}\right): \delta(\mathrm{ppm})$ $141.2,139.2,130.1,122.7,102.0,79.7,77.4,77.0,74.5$,

Table 1. Percentage of mortality exhibited by stigmasterol-3-Oglucoside

\begin{tabular}{lccc}
\hline & \multicolumn{3}{c}{ Percentage mortality* } \\
\cline { 2 - 4 } Stigmasterol-3-O-glucoside (ppm) & Four days & Seven days & 15 days \\
\hline Control & - & - & - \\
1 & - & - & 100 \\
2 & - & 20 & 100 \\
5 & 30 & 50 & 100 \\
10 & 70 & 100 & 100 \\
\hline
\end{tabular}

*Fifteen larvae were used for each concentration.

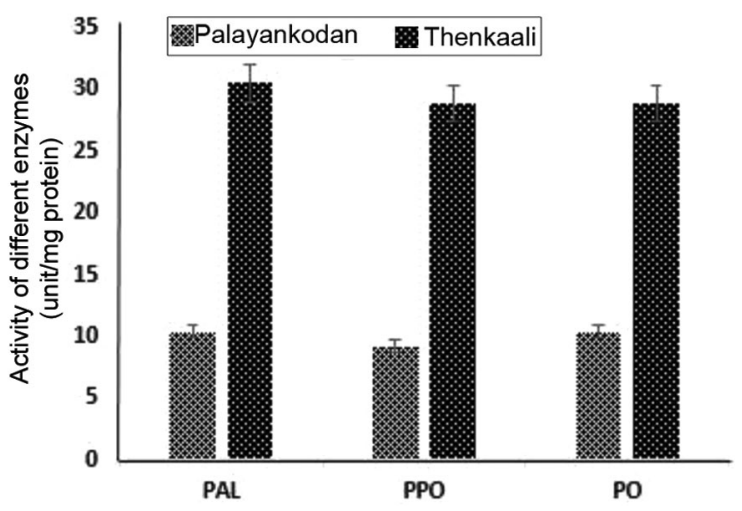

Figure 3. Activity of host-plant enzymes of resistant and susceptible Musa cultivars. All values are mean $\pm \mathrm{SD}, n=6$. Value of each parameter is significantly different in Duncan's multiple range test at 0.05 level.

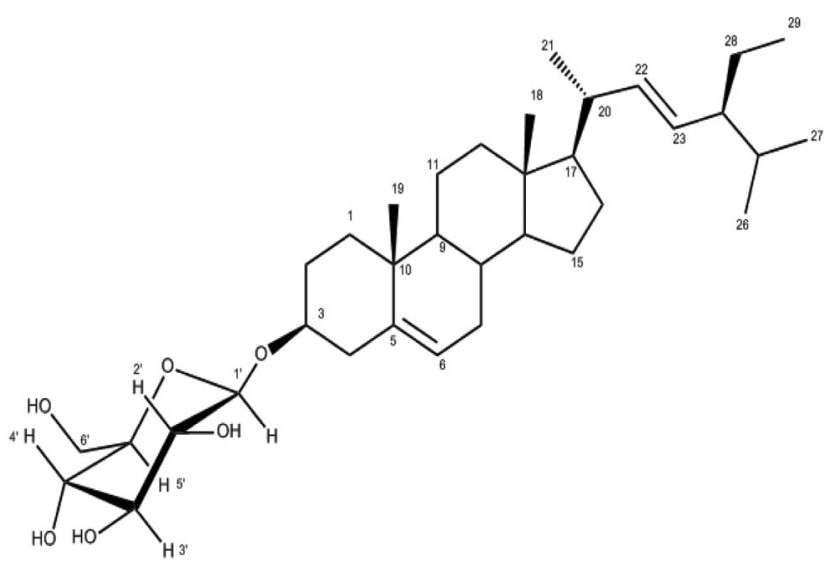

Figure 4. Structure of stigmasterol-3-O-glucoside.
$71.1,62.4,57.7,56.8,51.1,50.7,43.1,39.4,38.1,37.5$, $36.9,32.7,32.6,30.4,30.1,25.0,23.4,21.8,21.5,21.3$, $19.8,19.4,12.7,12.4$.

${ }^{13} \mathrm{C}$ NMR spectrum showed a total of 33 peaks which included four olefinic carbon signals $(\delta$ 141.2, 139.2, 130.1 and 122.7), similar to those of stigmasterol. However, there was a chemical shift value of $77.4 \mathrm{ppm}$ observed instead of $71 \mathrm{ppm}$ at C-3, indicating a different attachment at C-3 instead of the hydroxyl group. The attachment at $\mathrm{C}-3$ was found as glucose moiety from the peaks between $\delta 3.28-3.93$ and 4.47 in ${ }^{1} \mathrm{H}$ NMR, and carbon signals at $\delta 102.0,62.4,71.1,74.5,77.0$ and 79.7 in the ${ }^{13} \mathrm{C}$ NMR spectrum ${ }^{29}$. The mass data $(\mathrm{m} / \mathrm{z} 575.2375$ $[\mathrm{M}+\mathrm{H}]^{+}$) further confirmed the presence of sugar attachment to the stigmasterol skeleton. The ${ }^{13} \mathrm{C}$ NMR values of the compound were once again matched with the literature values and the compound was confirmed as stigmasterol-3-O-glucoside ${ }^{30}$.

The larvae in the pseudostem (100 g) which was administrated with $1 \mathrm{mg}$ (10 ppm) of active compound stopped feeding within $24 \mathrm{~h}$; thereafter, no feeding sounds were heard. Table 1 shows the percentage mortality induced by stigmasterol-3- $O$-glucoside at different concentrations, viz. from 1 to $10 \mathrm{ppm}$. At higher concentration of 5 and $10 \mathrm{ppm}$, the larvae became immobile from the fourth day onwards, and died between the sixth and eighth day. Even though the larvae in pseudostem at $1 \mathrm{ppm}$ concentration of stigmasterol-3-O-glucoside did not die even after one week, they died after 15 days without undergoing pupation. No feeding sounds were heared after seven days, which is an indication that the larvae stopped feeding on the seventh day at $1 \mathrm{ppm}$. They were weak and flaccid, and unable to feed or enter into the pseudostem.

Toxicity of stigmasterol-3-O-glucoside in $O$. longicollis larvae resulted in dose-dependent haemocytopenia in the haemolymph (Figure 5). The differential count also

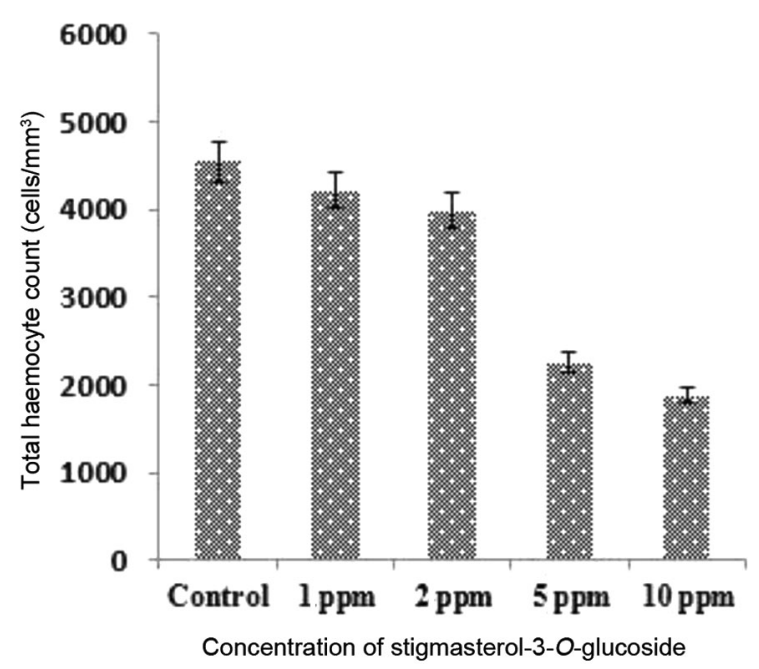

Figure 5. Effect of stigmasterol-3-O-glucoside on total haemocyte count. All values are mean $\pm \mathrm{SD}, n=6$. Value of each parameter is significantly different in Duncan's multiple range test at 0.05 level. 


\section{RESEARCH ARTICLES}

showed significant change during toxicity, indicating imbalance on the proportionate distribution of haemocytes. Among the different populations of haemocytes, the number of granulocytes showed a sharp increase but the number of plasmatocytes showed a sharp decrease (Figure 6).

Stigmasterol-3-O-glucoside intoxication at doses of 5 and $10 \mathrm{ppm}$ resulted in sharp elevation of haemolymph protein in $O$. longicollis larvae (Figure 7). Along with hyperproteinemia, sharp qualitative changes in protein profile, indicating appearance of new protein bands and disappearance of existing bands were observed (Figure 8). Sharp elevation of the content of haemolymph protein was clearly visible in the electropherogram. The changes in protein profile specifically at bands of molecular

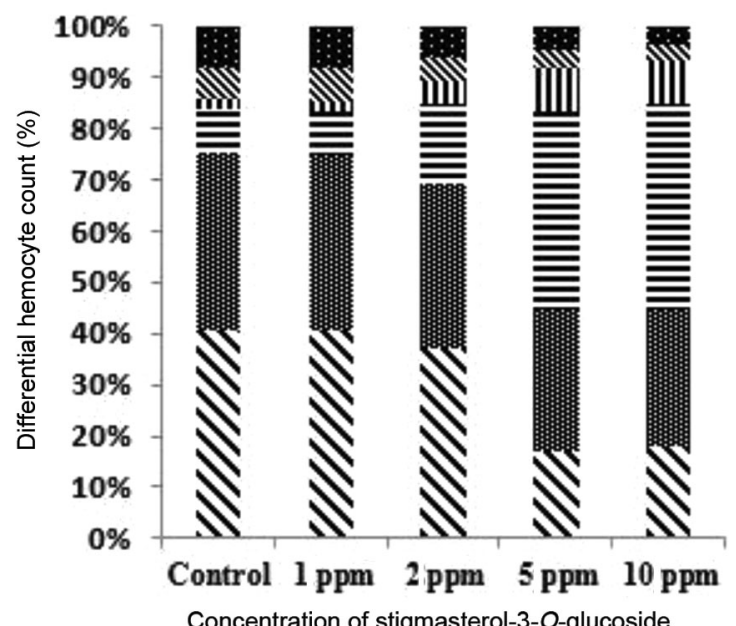

Plasmatocyte Prohemocyte $=$ Granulocyte
I Oenocytoid \& Spherulocyte RAdipohemocyte

Figure 6. Effect of stigmasterol-3-O-glucoside on differential haemocyte count.

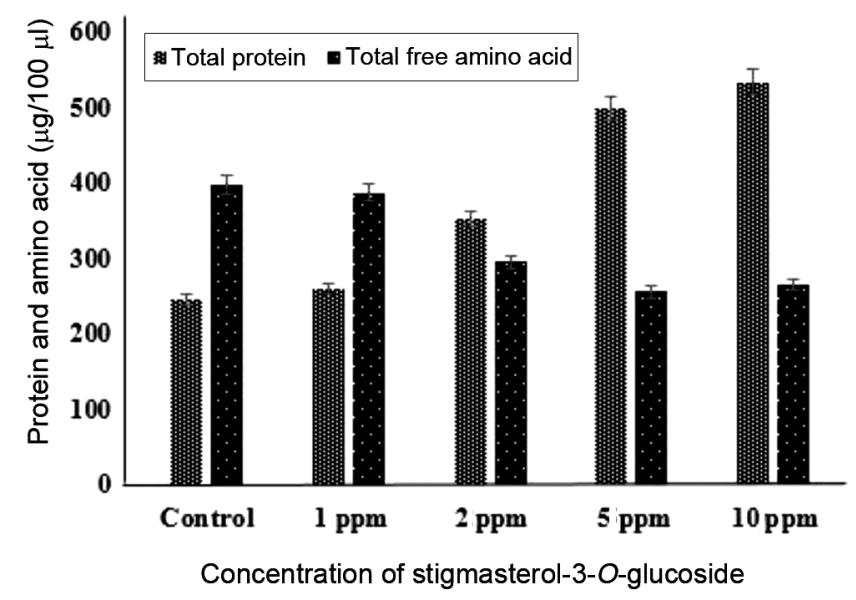

Figure 7. Effect of stigmasterol-3-O-glucoside on total protein and total free amino acids. All values are mean $\pm \mathrm{SD}, n=6$. Value of each parameter is significantly different in Duncan's multiple range test at 0.05 level. weight $64.53,49.73,36,36.52,30.48$ and $21.23 \mathrm{kDa}$ are indicated as arrows in the electropherogram. Significant decrease in the content of free amino acids was also observed at 5 and $10 \mathrm{ppm}$ concentration of the larvicide (Figure 7). Significant elevation of haemolymph uric acid (Figure 9) was observed in intoxicated larvae. The activity of cathepsin D showed a sharp elevation (Figure 10), but another protein-degrading enzyme, viz. leucine amino peptidase (LAP) showed sharp inhibition of activity (Figure 11). Significant elevation in the activities of aspartate amino transferase and alanine amino transferase were also observed in the larvae intoxicated with stigmasterol3-O-glucoside (Figure 12).

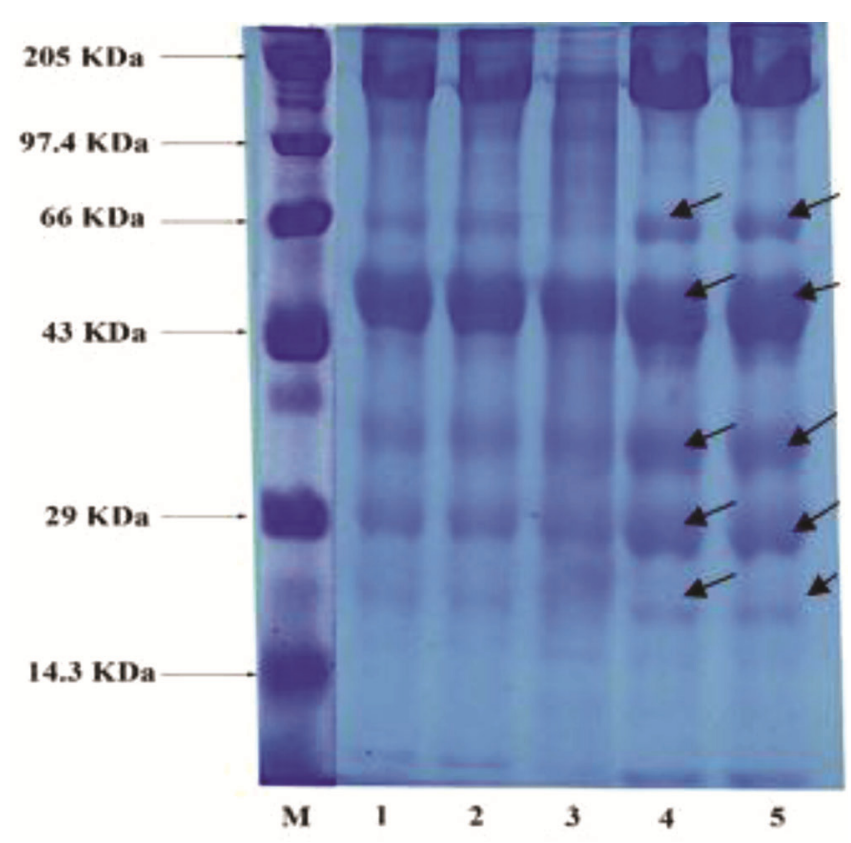

Figure 8. Electropherogram showing the effect of stigmasterol-3-Oglucoside on the haemolymph protein. Lane M, Marker; 1, control; 2, $1 \mathrm{ppm} ; 3,2 \mathrm{ppm} ; 4,5 \mathrm{ppm}$ and 5, $10 \mathrm{ppm}$. Thick bands, viz. 64.53, $49.3,36,36.52,30.48$ and $21.23 \mathrm{kDa}$ are indicated by arrows.

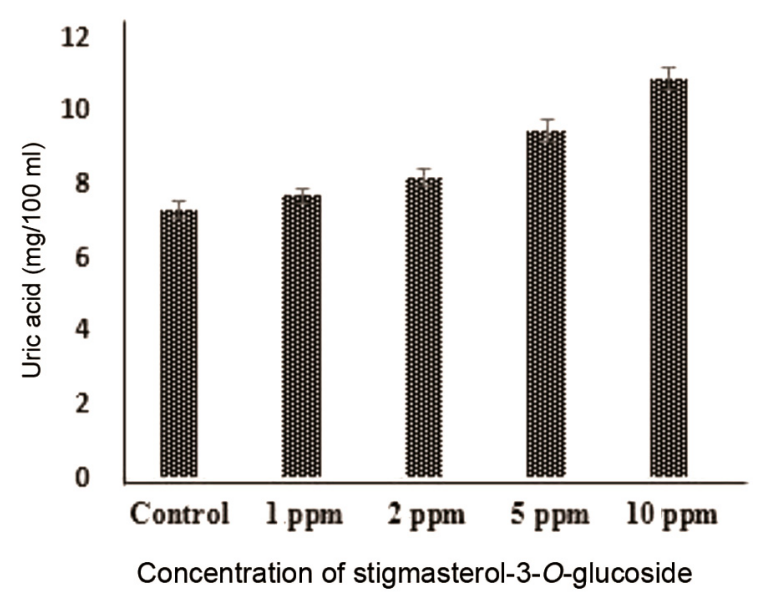

Figure 9. Effect of stigmasterol-3-O-glucoside on uric acid content. All values are mean $\pm \mathrm{SD}, n=6$. Value of each parameter is significantly different in Duncan's multiple range test at 0.05 level.

CURRENT SCIENCE, VOL. 118, NO. 6, 25 MARCH 2020 
$\beta$-Ecdysone is a steroid hormone which plays a major role in insect metamorphosis. Larvae reared in the pseudostem containing different concentrations of stigmasterol-3-O-glucoside caused a dose-dependent elevation in the activity of the enzyme 20-hydroxy ecdysone monoxygenase responsible for converting $\alpha$-ecdysone to $\beta$-ecdysone. Figure 13 shows the effect of stigmasterol-3$O$-glucoside on the activity of 20 -hydroxy ecdysone monoxygenase.

\section{Discussion}

Host-plant resistance is the most viable and sustainable strategy for the management of agriculturally important

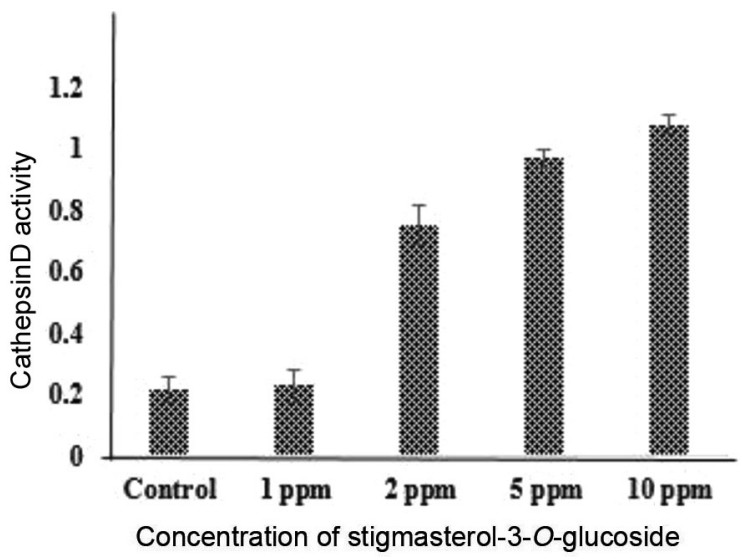

Figure 10. Effect of stigmasterol-3-O-glucoside on cathepsin D activity. All values are mean $\pm \mathrm{SD}, n=6$. Value of each parameter is significantly different in Duncan's multiple range test at 0.05 level.

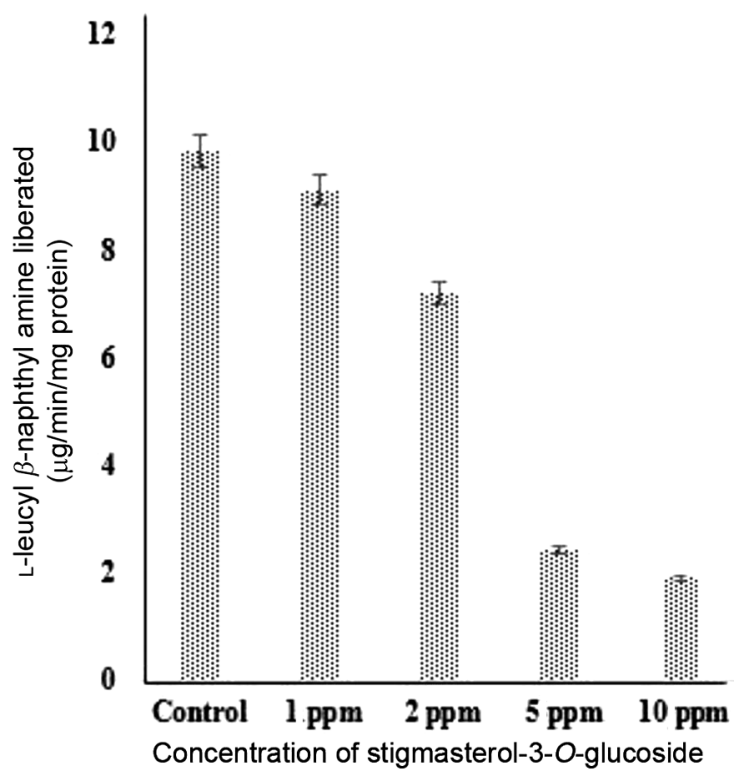

Figure 11. Effect of stigmasterol-3-O-glucoside on the activity of leucine amino peptidase. All values are mean $\pm \mathrm{SD}, n=6$. Value of each parameter is significantly different in Duncan's multiple range test at 0.05 level. insect pests. Field study and laboratory experiments on 85 Musa cultivars from different agro-ecosystems in Kerala, showed that the cultivars with high content of TP, TF and high activity of PAL, PPO and PO can cause allelopathy in $O$. longicollis larvae ${ }^{8-10}$. Isolation of a steroid glycoside which is highly toxic to the larvae which are completing their life cycle within the Musa cultivars is new to science, but stigmasterol has been isolated from many plants and the compound isolated from the bark of Butea monosperma with hypoglycaemic activity in experimental animals ${ }^{31}$. Crushed juice of fresh pseudostem of Musa cultivar Thenkaali is used as a remedy for hyperacidity and urolithiasis among villagers of Chittar in Kerala $^{8}$. Antiulcerogenic activity of two acyl steryl glycosides, sitoindoside I and sitoindoside II, has been reported from peeled fruits of another Musa cultivar from India $^{32}$.

Allelopathy induced by the host plant (Thenkaali) through stigmasterol-3-O-glucoside on the larvae within

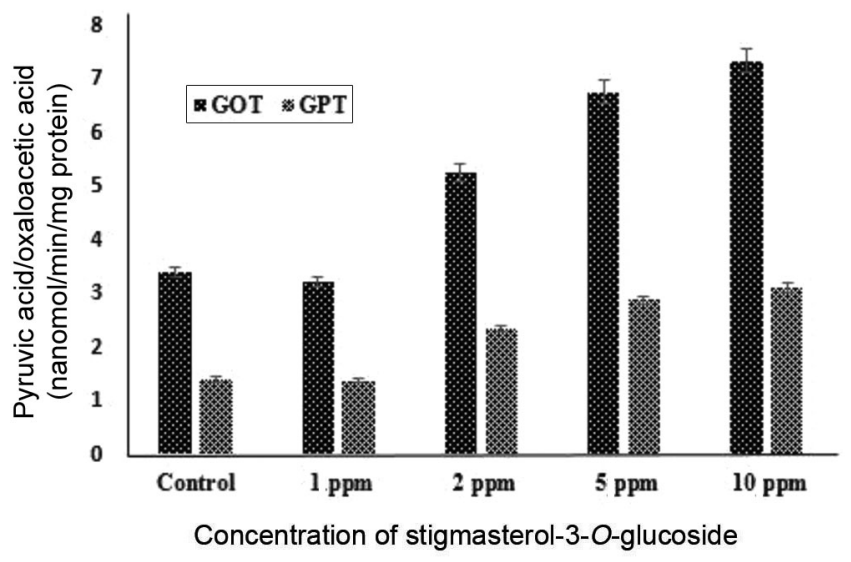

Figure 12. Effect of stigmasterol-3-O-glucoside on the activity of transaminases. All values are mean $\pm \mathrm{SD}, n=6$. Value of each parameter is significantly different in Duncan's multiple range test at 0.05 level.

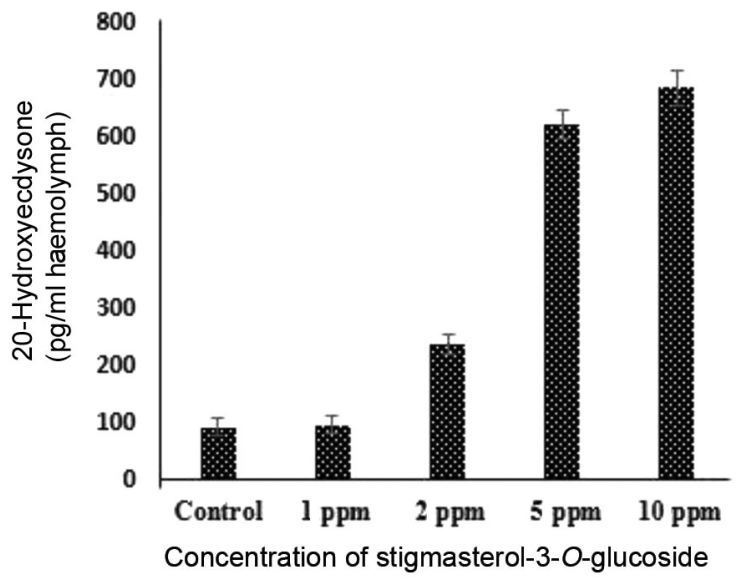

Figure 13. Effect of stigmasterol-3-O-glucoside on the activity of 20 -hydroxy ecdysone monoxygenase. All values are mean $\pm \mathrm{SD}, n=6$. Value of each parameter is significantly different in Duncan's multiple range test at 0.05 level. 
the pseudostem was not directed against any particular metabolism, but it affected transamination, protein degradation, protein profile of haemolymph, endocrine disruption and haemocytes. Attack on plasmatocytes and granulocytes will result in a defective immune system. Haemocytes of the intoxicated larvae showed a sharp decrease in number. Widespread cytopathological changes were induced by the live cultivar Thenkaali, on larvae of $O$. longicollis during laboratory rearing ${ }^{33}$. This type of haemocytopaenia was also observed in Dysercus sirgentatus and Papilo demoleus on intoxication by azadirectin $^{34}$. In the present study, stigmasterol-3-O-glucoside caused sharp increase in the number of granulocytes and decrease in the number of plasmatocytes. Plasmatocytes and granulocyes are major cell types responsible for immune defence in insects. Plasmatocytes are more involved in engulfing non-self or invading microorganisms, while granulocytes are involved in removing cell debris $^{35}$. Cytopathological studies revealed that most of the cells affected during toxicity were plasmotocytes, and this may be the reason for the low number of plasmatocytes observed during differential count. The debris of the lysed plasmatocytes in the haemolymph may be the reason for increase in the number of granulocytes. Such result was also observed in Rhyncophores ferrugineus, experimentally infected by $B$. thuringiensis ${ }^{36}$.

Hyperprotenemia of the haemolymph has been reported in many insect larvae in response to various stressors, such as entomopathogenic bacterial infection in larvae Oryctes rhinoceros ${ }^{37}$. So hyperprotenemia exhibited by $O$. longicollis larvae on intoxication by stigmasterol-3-Oglucoside may be a generalized defence response of insects against adverse conditions. In association with hyperprotenemia, sharp decrease in the free amino acids pool was observed in larvae intoxicated by stigmasterol3-O-glucoside, and this is in agreement with the observations in a previous study ${ }^{37}$. The reason for the sharp decrease in amino acids in the free amino acids pool may be either due to their utilization for the synthesis of new proteins, or due to their excessive catabolism.

Activity of LAP, an exopeptiase, was inhibited during allelopathy by the active molecule, which simultaneously elevated the activity of another proteolytic enzyme cathepsin D, an aspartate protease. This type of antagonistic response of these two enzymes was observed in Oryctes rhinoceros under various stress conditions and also in other insects ${ }^{34,38}$. Activity of another set of related enzymes was affected by the toxic compound during allelopathy. Activity of both transaminases were (AsAT and AlAT) elevated during toxicity. These enzymes are responsible for conversion of amino acids to keto acids for their transport into the Krebs cycle. Elevated transaminase activity was reported in Spodoptera litura on infection by $B$. thuringiensis ${ }^{39}$ and also in $O$. rhinoceros ${ }^{37}$. Exponential accumulation of $\beta$-ecdysone leading to cessation of feeding was one of the reasons for the death of larvae in the pseudostem containing different concentrations of the active compound. It is well established that elevation of 20-hydroxy ecdysone in the haemolymph caused cessation of feeding activity in almost all final instar larvae and pupae of holometabolous insects ${ }^{40}$.

\section{Conclusion}

Presence of a highly toxic larvicidal molecule in an indigenous Musa cultivar against the chief pest of Musa cultivars paves the way for its use in pest management. Identification of the genetic mechanism involved in the synthesis of this larvicide and its subsequent modulation in susceptible cultivars need further studies. Development of host-plant resistance is the sustainable strategy for pest management.

1. Nair Ashalatha, S., Chee, H. T., Schwarzacher, T. and Harrison, P. H., Genome classification of banana cultivars from South India using IRAP markers. Euphytica, 2005, 144, 285-290.

2. Simmonds, N. W. and Shepherd, K., The taxonomy and origins of the cultivated bananas. J. Linn. Soc. London, Bot., 1955, 55, 302312 .

3. Simmonds, N. W., Bananas, Longman, New York, USA, 1966, 2nd edn.

4. Cheesman, E. E. and Larter, L. N. H., Genetical and cytological studies of Musa-III. Chromosome numbers in the musaceae. J. Genet., 1935, 30, 32-52.

5. Samson, J. A., Tropical Fruits, Longman, New York, USA, 1982.

6. Sandoval, F. J. A., Tapia, F. A. C., Muller, L. and Villalobos, A. V., Obervaciones sobrela variabilidad encontrada en plantas micropropagades de Musa cv. Falso Cuerno AAB. Fruits, 1991, 46, 533-539.

7. Kavitha, K. J., Murugan, K. and Evans, D. A., Allelopathic interactions of certain Musa cultivars against O. longicollis. Entomon., 2015, 40, 209-220.

8. Kavitha, K. J., Murugan, K. and Evans, D. A., Screening of wild and cultivars of banana of Kerala, India using score card method and its resistance against Odoiporus longicollis Olivier. Phyromorphology, 2015, 65, 121-126.

9. Ajitha, T., Kavitha, K. J., Shabith Raj, K. and Evans, D. A., Distribution of flavonoids, phenols and related enzymes in Musa cultivars and their role in resisting infestation and causing mortality in Odoiporus longicollis (Olivier). Int. J. Trop. Agric., 2018, 36, 37-44.

10. Kavitha, K. J., Shabith Raj, K., Murugan, K. and Evans, D. A., Allelopathic effects of high contents of phenols and flavonoids on Odoiporus longicollis (Olivier). Allelopathy J., 2020, 49, 99-112.

11. Alagesan, A., Tharani, G., Padmanaban, B., Siva Vijayakumar, T. and Manivannan, S., Screening and characterization of developing resistant cultivar against Odoiporus longicollis (Olivier) (Coleoptera: Curculionidae) using reference genotypes in India. Int. J. Pharm. Pharm. Sci., 2016, 8, 223-226.

12. Mayr, U., Treutter, D., Santos-Buelga, C., Bauer, H. and Feucht, W., Developmental changes in the phenol concentrations of 'Golden delicious' apple fruits and leaves. Phytochemistry, 1995, 38, 1151-1155.

13. Chang, C. C., Yang, M. H., Wen, H. M. and Chern, J. C., Estimation of total flavonoid content in propolis by two complementary colometric methods. J. Food Drug Anal., 2002, 10, 178-182.

14. Whetten, R. W. and Sederoff, R. R., Phenylalanine ammonia-lyase from loblolly pine: purification of the enzyme and isolation of complementary DNA clones. Plant Physiol., 1992, 98, 380-386. 
15. Hammerschmidt, R., Nuckles, E. M. and Kuć, J., Association of enhanced peroxidase activity with induced systemic resistance of cucumber to Colletotrichum lagenarium. Physiol. Plant Pathol., 1982, 20.

16. Mayer, A. M., Harel, E. and Ben-Shaul, R., Assay of catechol oxidase - a critical comparison of methods. Phytochemistry, 1966, 5, 783-789.

17. Evans, D. A. and Kaleysaraj. R., Larvicidal efficacy of quassin against Culex quinquefasciatus. Indian J. Med. Res., 1991, 93, 324-327.

18. Evans, D. A., Isolation, identification and mode of action of a mosquito larvicide from Quassia amara, $\mathrm{Ph} \mathrm{D}$ thesis, University of Kerala, 1991, p. 29.

19. Jones, J. C., The hemocytes of Rhodnius prolixus Stal. Biol. Bull., 1965, 129, 282-294.

20. Lowry, O. H., Rosebrough, N. J., Farr, A. L. and Randall, R. J., Protein measurement with the Folin phenol reagent. J. Biol. Chem., 1951, 193, 265-275.

21. Spice, J. R., Colorimetric procedures for amino acids. Science Direct, 1957, pp. 467-477.

22. Reitman, S. and Frankel, S., A colorimetric method for the determination of serumglutamic oxalacetic and glutamic pyruvic transaminases. Am. J. Clin. Pathol., 1957, 28, 56-63.

23. Amador, E., Zimmerman, S. and Wacker, W. E., Urinary alkaline phosphatase activity. II. An analytical validation of the assay method. JAMA, 1963, 185, 953-957.

24. Mycek. M. J., Methods in Enzymology, Academic Press, New York, USA, 1970

25. Porcheron, P., Moriniere, M., Grassi, J. and Pradelles, P., Development of an enzyme immunoassay for ecdysteroids using acetylcholinesterase as label. Insect Biochem., 1989, 19, 117-122.

26. Mahler, H. R., Quantification of uric acid in body fluids. J. Biol. Chem., 1955, 216, 625-641.

27. Laemmli, U. K., Cleavage of structural proteins during the assembly of the head of bacteriophage T4. Nature, 1970, 227, 680-685.

28. Daniel, W. W., Biostatistics - A Foundation for Analysis in Health Sciences, Georgia State University, Wiley and Sons (Asia), 2006, 7 th edn.

29. Ridhay, A., Noor, A., Soekamto, N. H., Harlim, T. and van Altena, I., A stigmasterolglycoside from the root wood of Melochia umbellata (Houtt) Stapf Var. degrabrata K. Indones. J. Chem., 2012, 12, 100-103.

30. Kojima, H., Sato, N., Hatano, A. and Ogura, H., Sterol glucosides from Prunella vulgaris. Phytochemistry, 1990, 29, 2351-2355.
31. Panda, S., Jafri, M., Kar, A. and Meheta, B. K., Thyroid inhibitory, antiperoxidative and hypoglycemic effects of stigmasterol isolated from Butea monosperma. Fitoterapia, 2009, 80, 123-126.

32. Ghosal, S., Steryl glycosides and acyl steryl glycosides from Musa paradisiaca. Phytochemistry, 1985, 24, 1807-1810.

33. Kavitha, K. J., Murugan, K. and Evans, D. A., Cytopathological and haematological changes in Odoiporus longicollis [Olivier] grub by Aattinkombu and Thenkaali, the two pest resistant Musa cultivars identified in Kerala. J. Entomol. Res., 2016, 40, 27-33.

34. Pandey, J. P. and Tiwari, R. K., Neem based insecticides interaction with development and fecundity of red cotton bug, Dysdercus cingulatus Fab. Int. J. Agric. Res., 2011, 6, 335-346.

35. Ling, E. and Yu, X. Q., Hemocytes from the tobacco hornworm Manduca sexta have distinct functions in phagocytosis of foreign particles and self dead cells. Dev. Comp. Immunol., 2006, 30, 301-309.

36. Manachini, B., Arizza, V., Parrinello, D. and Parrinello, N., Hemocytes of Rhynchophorus ferrugineus (Olivier) (Coleoptera: Curculionidae) and their response to Saccharomyces cerevisiae and Bacillus thuringiensis. J. Invertebr. Pathol., 2011, 106, 360-365.

37. Adhira, M. N., Syamala Devi, G. and Evans, D. A., Effect of Bacillus thuringiensis Israelensis infection on the biochemical and hematological profile of hemolymph of Oryctes rhinoceros [L.] (Coleoptera: Scarabaeidae). Entomon, 2010, 35, 241-246.

38. Saleem, M. A., Wilkins, R. M., Mantle, D. and Shakoori, A. R., In vivo effects of cyfluthrin on proteolytic enzyme activities of malathion-resistant and susceptible strains of Tribolium castaneum. Pak. J. Zool., 2004, 36, 239-245.

39. Kim, Y. I. et al., Modulation of MnSOD protein in response to different experimental stimulation in Hyphantria cunea. Comp. Biochem. Physiol. Part B, 2010, 157, 343-350.

40. Muramatsu, D., Kinjoh, T., Shinoda, T. and Hiruma, K., The role of 20-hydroxyecdysone and juvenile hormone in pupal commitment of the epidermis of the silkworm, Bombyx mori. Mech. Dev., 2008, 125, 411-420

ACKNOWLEDGEMENT. We thank the Kerala State Council for Science, Technology and Environment, Government of Kerala, for providing funds through a major research project.

Received 14 December 2017; revised accepted 18 December 2019

doi: $10.18520 / \mathrm{cs} / \mathrm{v} 118 / \mathrm{i} 6 / 946-953$ 